\title{
CREATIVE STRATEGIES IN NAVIGATING THE NEW NORMAL: ADVANCING THE CONTRIBUTIONS OF THE ISPRS STUDENT CONSORTIUM AS AN INTERNATIONAL ORGANIZATION
}

\author{
S. R. Reyes ${ }^{1}$, C. Cruz $^{2}$, M. Üstüner ${ }^{3}$, C. Jjuuko ${ }^{4}$, and S. Guliyeva ${ }^{5}$ \\ ${ }^{1}$ United Nations University - Institute for the Advanced Study of Sustainability, \\ 5 Chome-53-70 Jingumae, Shibuya City, Tokyo, Japan - sherylrose.reyes@ gmail.com \\ ${ }^{2}$ Department of Geography, Trinity College Dublin, Dublin 2, Ireland \\ ${ }^{3}$ Artvin Coruh University, Seyitler, Centrum, Artvin, Turkey \\ ${ }^{4}$ Makerere University, University Rd, Kampala, Uganda \\ ${ }^{5}$ Aerospace Monitoring of Environment Department, National Aviation Academy, Mardakan av.30, Baku, Azerbaijan
}

\section{Commission V}

KEY WORDS: ISPRS SC, online learning, social media, pandemic, youth

\begin{abstract}
:
The International Society for Photogrammetry and Remote Sensing Student Consortium (ISPRS SC) is an international student organization representing the youth in the ISPRS. The COVID-19 pandemic adversely affected students and young professionals around the world because of country-wide lockdowns and comprehensive quarantine and social distancing measures. This situation led to the implementation of distance learning and remote work. The Consortium organized different activities in support of students and young professionals during the global health crisis. Despite the challenges and necessary adjustments, the unprecedented situation helped the organization adapt to change and encouraged us to revisit our roles as an international organization. The ISPRS SC hosts and coordinates activities and events both in person and online, including the Webinar Series, the publication of the SpeCtrum and the summer schools. During the pandemic, we improved our existing activities to provide support to our members and to the scientific community in general as we navigate major lifestyle changes and become more adept in using technology in our day-to-day lives. We also introduced new initiatives such as the Virtual Rooms and the GeoMixer, and continued to work in partnership with different organizations in remote sensing, photogrammetry and spatial information science. Moreover, we continued to strengthen our connection to the ISPRS through a collaboration with the ISPRS White Elephant Club and for a special event honouring one of the most important figures in the Society and in the profession. With all these activities organized during this challenging time, the Consortium experienced growth in terms of organizing and improving its activities, our roles as an international organization, and our online presence. The Consortium has also taken steps for continuity and sustained relevance to both the youth and ISPRS.
\end{abstract}

\section{INTRODUCTION}

The International Society for Photogrammetry and Remote Sensing Student Consortium (ISPRS SC) represents the youth in the ISPRS. The ISPRS SC is a network of students, young researchers and professionals across the globe, interested in photogrammetry, remote sensing and spatial information science. The Consortium shares the same vision with the Society and, according to its Statutes (ISPRS SC, 2019a), "advocates for imaging and geospatial science for informed, scientifically valid, and technologically sound observations of Earth conditions and trends that lead to improved and effective decision-making."

The outbreak of severe acute respiratory syndrome coronavirus 2 (SARS-CoV-2) in 2019, known to the general public as COVID19 , was officially declared by the World Health Organization (WHO) as a global pandemic in March 2020 (World Health Organization, 2020). Many countries responded to this global health crisis by imposing travel bans, country-wide lockdowns, community quarantines, and comprehensive social distancing measures. The pandemic significantly disrupted our daily lives, forcing many people around the world to navigate a new way of living through technology. According to the United Nations Educational, Scientific and Cultural Organization (UNESCO), about 188 countries suspended schools and universities nationwide in support of country-wide lockdowns and affected about 1.5 billion of the youth population (Lee, 2020; UNESCO, 2021).
In this paper, we discuss how the ISPRS SC experienced growth during a global health crisis by adapting to change, continuing and improving our existing activities, and developing new initiatives that could help the youth during this challenging time. We also describe the roles of the Consortium and how the organization can continue to contribute and sustain relevance to the youth, the ISPRS, and our scientific community.

\section{EXPERIENCING GROWTH DURING A GLOBAL HEALTH CRISIS}

\subsection{Challenges for the Youth During the Pandemic}

The youth were confronted with a number of challenges during this pandemic. In addition to the fear of infection, other known stressors during quarantine included frustration and boredom (Brooks et al., 2020). These stressors affect an individual's daily routine and lead to an increased sense of isolation. Students also experienced frustration and boredom as countries around the world imposed lockdowns and transitioned to online learning (Aristovnik et al., 2020).

Previous studies exposed that graduate students are more than six times as likely to experience anxiety and depression. As such, even prior to the pandemic, a call to action from the academic community was made to address this growing concern (Evans et al., 2018; Pain, 2018). School and university closures have affected students' access to resources, including mental health support, peer support groups, and face-to-face services (Lee, 
2020). Another study investigating the mental health of students prior and during the COVID-19 pandemic showed increased stress, anxiety, and loneliness among the participants (Elmer, Mepham and Stadtfeld, 2020). Moreover, uncertainties and worries about health, family and friends, and their future replaced the fear of missing out on their social networks.

On a broader scale, this interruption in education systems around the world demonstrated that the transition to virtual learning took time and effort from both students and educators and highlighted the inequalities among students in developing and developed countries (Daniel, 2020; GEM Report, 2020; Mathewson, 2020).

\subsection{Adapting to Change}

The global health crisis also provided a window of opportunity for international organizations. Virtual exchanges could foster a sense of connection (Van Bavel et al., 2020) and giving and providing support to peers could contribute to one's psychological well-being. The pandemic also resulted in the wide use of digital interaction formats for scientific exchange with numerous conferences, lectures, and meetings hosted since the outbreak (Schwarz et al., 2020). Furthermore, going digital could lead to increased inclusivity and diversity, flexibility in terms of time and cost effectiveness as well as environmental sustainability (Bonnett, 2016).

Given the experience of leading an international organization through technology, the Internet, and, more recently, social media, the ISPRS SC was able to adapt and navigate the "new normal" by improving our existing activities and introducing new virtual initiatives that kept our members connected and up-todate with recent advances in remote sensing, photogrammetry, and spatial information science.

\subsubsection{Virtual Rooms}

The ISPRS SC Virtual Rooms were launched in April 2020 as the organization's response to country-wide lockdowns and the need to stay at home. The Board of Directors was composed of international students and young professionals and we very well understood the challenges brought about by the pandemic, including the isolation, living away from our families and friends, and the anxiety and uncertainty about the future. The Virtual Rooms were designed to serve as venues for open discussion, informal lectures, and the exchange of ideas. This initiative also provided a place for members to meet each other, converse with organizations and leading experts in the scientific community, and connect with ISPRS experts. Furthermore, this initiative supported the youth in adjusting to a new way of strengthened communication, making adjustments to their current lifestyles, maintaining focus and attention on research, and keeping up with what truly matters in life.

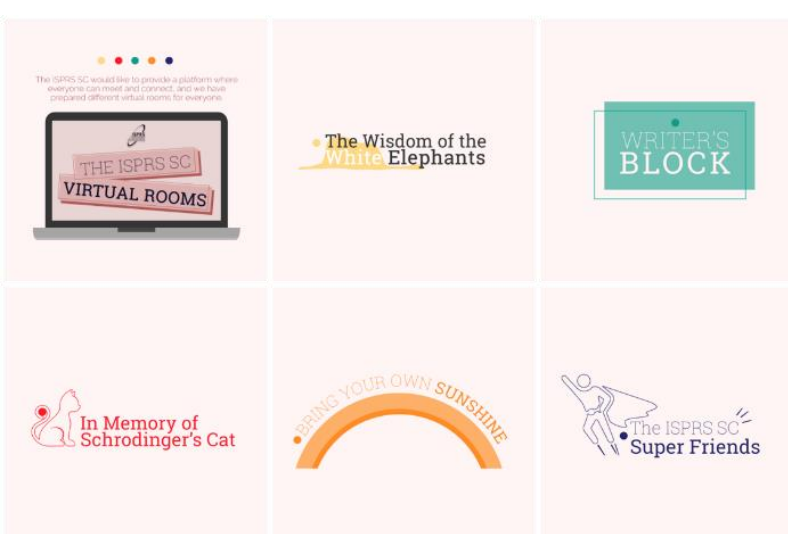

Figure 1. The Virtual Rooms hosted in April 2020 featured five different rooms.

The Virtual Rooms featured five different rooms (Figure 1). There were three open rooms: In Memory of Schrödinger's Cat, Writer's Block and Bring Your Own Sunshine! These rooms were designed for informal meetings or discussions and were moderated by the Board of Directors and/or guest moderators. The other two rooms featured special guests. The Wisdom of the White Elephants, an exclusive room for members of the ISPRS White Elephant Club, facilitated lectures related to research, writing, and professional advice during the pandemic. The ISPRS $S C$ Super Friends was the room for invited guest speakers from organizations in remote sensing, photogrammetry, and spatial information science.

The Virtual Rooms were hosted from 5 April to 30 April 2020. We created a single registration for simplicity since it was hosted on an almost daily basis. We also intended for this initiative to be a venue where people could join if they were available or if they were interested in the topic of one of the upcoming Virtual Rooms. We recorded a total of 215 responses. About $46 \%$ of the registered participants were students, 39\% were young professionals and about $15 \%$ were classified as others (i.e., industry expert, faculty member, government employee). We had an average attendance of about 21 participants for the Wisdom of the White Elephants and The ISPRS SC Super Friends.

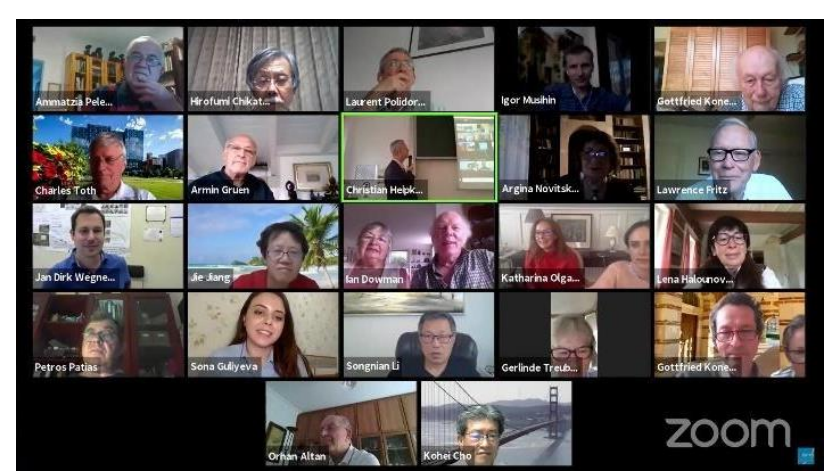

Figure 2. Some of the guests for Dr. Gottfried Konecny's birthday celebration in the ISPRS SC Virtual Rooms - The Wisdom of the White Elephants.

The Virtual Rooms also welcomed a collaboration and celebration with ISPRS and the ISPRS White Elephant club (Figure 2). On 17 June 2020, colleagues, friends, family and followers of Dr. Gottfried Konecny gathered in celebration of his $90^{\text {th }}$ birthday. Taken under the Virtual Rooms branding, the Wisdom of the White Elephants, and pertinently titled, "A Life for Photogrammetry and Remote Sensing," this event presented 
our members with a timeline of the experiences, contributions, and achievements of Dr. Konecny and a glimpse of his personal life. It was a very well-attended event with over 160 guests who celebrated and greeted him on this special occasion. An editorial related to this event was published in The Photogrammetric Record in September 2020 (Granshaw, 2020).

\subsubsection{Webinar Series}

Following a poll that we conducted on social media, the ISPRS SC hosted the Webinar Series in 2020 with a focus on the topics of deep learning and computer vision.

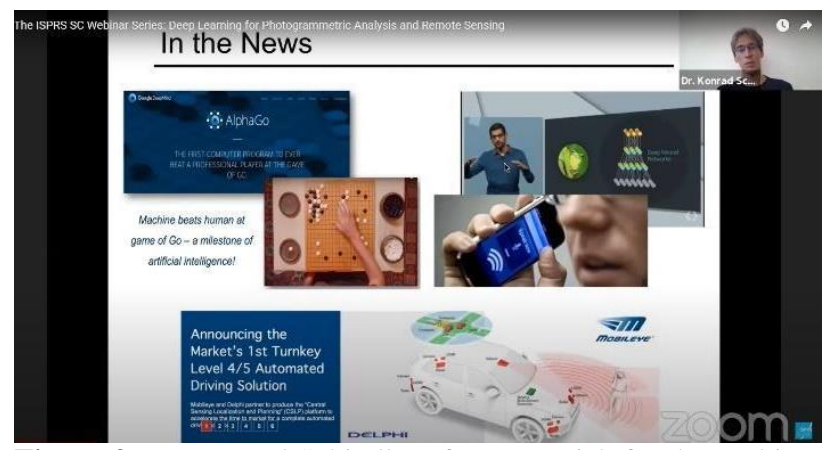

Figure 3. Dr. Konrad Schindler of ETH Zürich for the Webinar Series, presenting his lecture titled, "Deep Learning for Photogrammetric Analysis and Remote Sensing."

The first webinar, titled "Deep Learning for Photogrammetric Analysis and Remote Sensing," was held on 20 February 2020 with Dr. Konrad Schindler, a professor at the Department of Civil, Environmental and Geomatic Engineering, Institute of Geodesy and Photogrammetry in ETH Zürich, as guest speaker (Figure 3). The lecture provided an overview of deep learning and its applications in the era of big data. Dr. Schindler also discussed technical details about artificial neural networks and shared some of their ongoing research, including tropospheric path delays, mapping street-side trees, vegetation height from space and digital elevation model (DEM) filtering. A total of 91 participants joined this webinar.

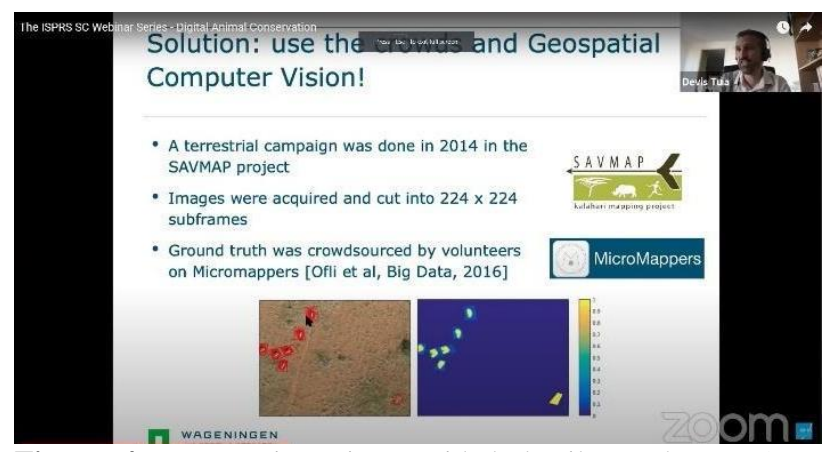

Figure 4. Dr. Devis Tuia provided details on how UAVs, together with field surveys, supported wildlife conservation.

The second webinar was on the topic of "Digital Animal Conservation - From Flying UAVs to Mapping with Deep Learning" and was hosted on 21 May 2020. Dr. Devis Tuia, who was then a professor at Wageningen University, the Netherlands (Figure 4), was guest speaker for this event. His lecture focused on how digital technologies such as advanced imaging and cutting-edge computer vision coupled with advanced deep learning methods could support wildlife conservation and protect biological diversity. Unmanned Aerial Vehicles (UAVs) could offer a great opportunity for monitoring the animals in the wild and deep learning could aid in the automation of counting animals with high accuracy. In addition, the lecture demonstrated possibilities for monitoring animal populations without damaging their habitats. About 94 participants from different parts of the world participated in this interesting webinar.

\subsubsection{Summer School}

The 6th edition of the IEEE-GRSS Young Professionals and ISPRS Student Consortium Brazil Summer School was converted to a virtual event with the theme "Emerging Trends in Remote Sensing Science and Applied Machine Learning."
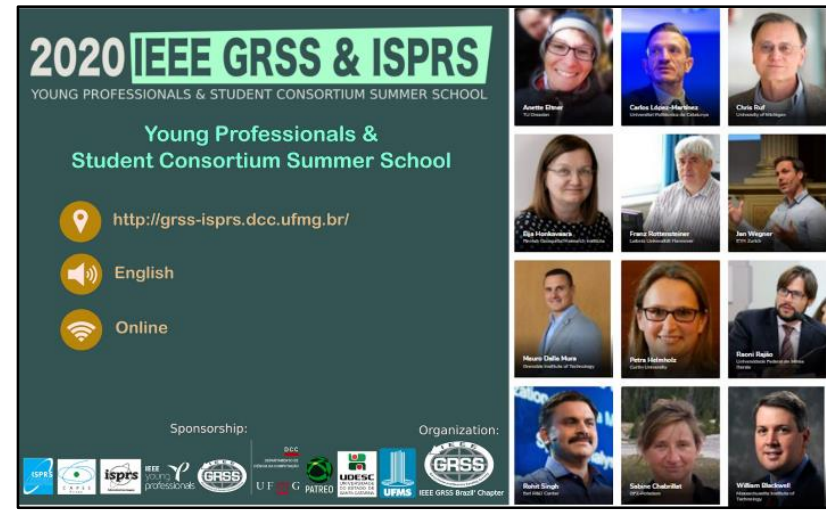

Figure 5. The speakers for the 6th IEEE GRSS Young Professionals and ISPRS SC Student Consortium Summer School.

The summer schools scheduled for 2020 were postponed due to the pandemic and the subsequent travel restrictions to many countries. However, the local organizers from Brazil, namely Universidade Federal de Minas Gerais (UFMG) and the IEEE Geoscience and Remote Sensing Society (IEEE-GRSS) Brazil Chapter, explored the possibility of delivering the lectures online every week from October to December 2020. A total of 12 lectures were live streamed via the popular online video-sharing platform YouTube on three channels (ISPRS SC, MS IEEEGRSS Student Chapter and Department of Computer Science, UFMG) featuring speakers from different countries (Figure 5). The summer school tackled various topics in photogrammetry, remote sensing, machine learning, and the capabilities of current and upcoming satellite missions.

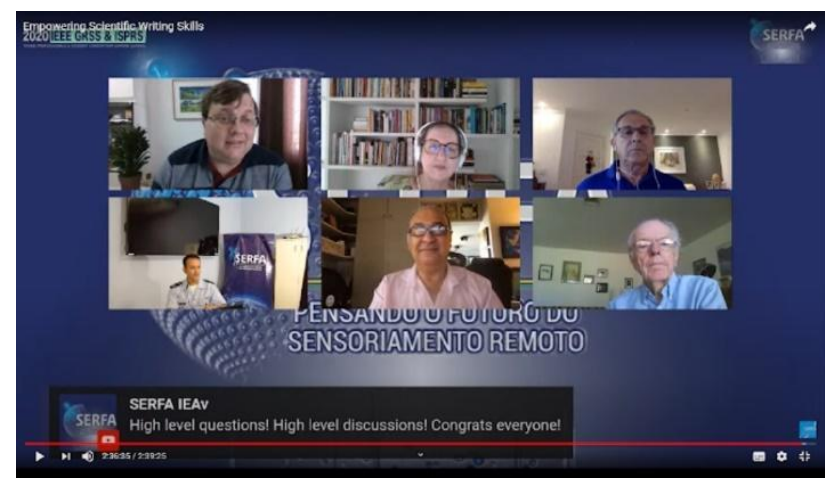

Figure 6. The special session in SERFA 2020 on "Empowering Scientific Writing Skills."

This summer school also co-hosted a special session in the 10th edition of the Remote Sensing for Defense Applications (Portuguese: Simpósio de Sensoriamento Remoto de Aplicações em Defesa, SERFA 2020), titled "Empowering Scientific Writing Skills." This special session discussed the scientific 
writing process and the importance of understanding the ethics of technical writing and gave valuable advice to the audience about publishing research in a respected journal (Figure 6).

\subsubsection{Newsletter}

In consideration of the adjustments necessary for living in the current pandemic, the SpeCtrum, the official Newsletter of the ISPRS SC, postponed the first issue of volume 14 for three months. We also decided on special issues that would be of great interest to our readers (Figure 7).

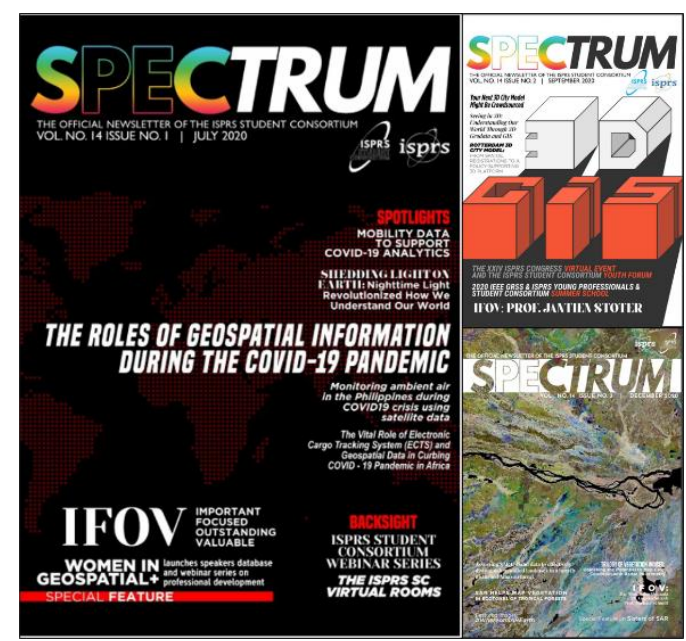

Figure 7. The three issues of the SpeCtrum published for volume 14 in 2020.

Geospatial information played a vital role in understanding the spread and impacts of COVID-19, and related research was featured in the first issue for volume 14 in 2020 (http://sc.isprs.org/files/sc/newsletter/ISPRS-SC-Spectrum-

Vol14-No1.pdf). This was followed by a special issue on 3D GIS that presented the advancements and state-of-the-art techniques in visualizing and modelling the real world (http://sc.isprs.org/files/sc/newsletter/ISPRS\%20SC\%20Spectru $\mathrm{m} \% 20 \mathrm{Vol} 14 \% 20 \mathrm{No} 2 . \mathrm{pdf})$. The final issue for the year promoted the applications of radar remote sensing, particularly synthetic aperture radar, and also highlighted some of the most notable researchers in the field (http://sc.isprs.org/files/sc/newsletter/ISPRS\%20SC_Vol14\%20 Issue3.pdf).

\subsubsection{GeoMixer}

The ISPRS Student Consortium, in collaboration with the Ladies of Landsat, Sisters of SAR, American Society for Photogrammetry and Remote Sensing (ASPRS) Student Advisory Council, Mato Grosso do Sul IEEE-GRSS (MS IEEEGRSS) Student Branch Chapter, and the Asian Association on Remote Sensing (AARS), started a monthly virtual event called GeoMixer. Inspired by the GeoMixers organized in previous conferences, this event provided a platform for remote sensing scientists at all career stages from around the world to build their professional networks.

The kick-off GeoMixer event was hosted in January 2021 with over 40 participants from across the globe. The initial registration for the event recorded the contact information of about 135 individuals interested in participating in the monthly GeoMixer events.

\subsection{Growth and Continuity}

\subsubsection{Membership and Online Presence}

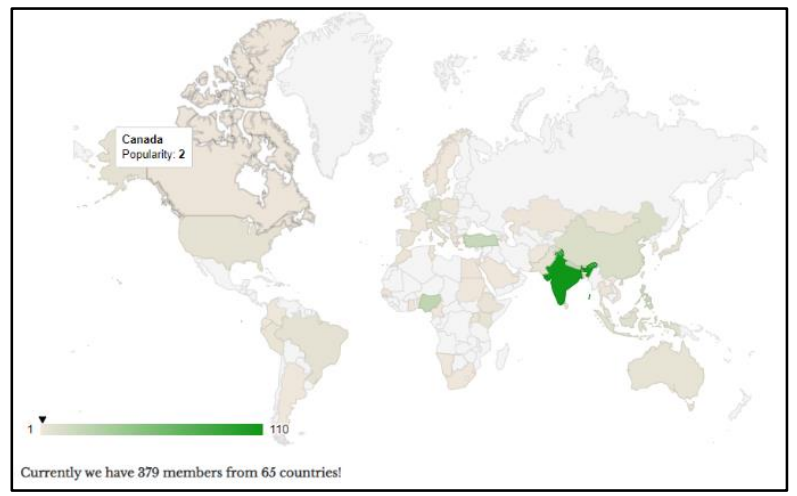

Figure 8. The members map available in the official ISPRS SC website (http://sc.isprs.org/members/members-map.html) indicating the geographic distribution of the organization's membership.

The membership registration of the ISPRS SC was revised in 2020 and at present, we currently have a total of 379 members with the new system for individual membership registration (Figure 8). Our social media following also continued to increase in our most active accounts. Note that all statistics indicated in this subsection were taken as of 4 February 2021.

Our Facebook group has about 7,038 members (https://www.facebook.com/groups/isprssc), 1,288 Twitter followers (@ISPRS_SC), and 391 subscribers on our YouTube channel (https://www.youtube.com/c/ISPRSSC). Table 1 lists the top five most popular videos on YouTube and their number of views as of early 2021.

Table 1. The top five most viewed videos on the ISPRS SC YouTube Channel.

\begin{tabular}{|c|c|c|}
\hline Video Title & Activity & $\begin{array}{l}\text { Number } \\
\text { of Views* }\end{array}$ \\
\hline $\begin{array}{l}\text { The Role of } \\
\text { Geosciences in } \\
\text { Achieving } \\
\text { Deforestation-Free } \\
\text { Supply Chains in Brazil }\end{array}$ & $\begin{array}{l}6^{\text {th }} \text { IEEE-GRSS } \\
\text { Young Professionals } \\
\text { and ISPRS Student } \\
\text { Consortium Brazil } \\
\text { Summer School }\end{array}$ & 2,739 \\
\hline $\begin{array}{l}\text { Deep Learning for } \\
\text { Photogrammetric } \\
\text { Analysis and Remote } \\
\text { Sensing }\end{array}$ & Webinar Series & 1,003 \\
\hline $\begin{array}{l}\text { Digital Animal } \\
\text { Conservation: From } \\
\text { Flying UAVs to } \\
\text { Mapping with Deep } \\
\text { Learning }\end{array}$ & Webinar Series & 886 \\
\hline $\begin{array}{l}\text { UAV Remote Sensing } \\
\text { for Hydro- } \\
\text { Morphological } \\
\text { Monitoring }\end{array}$ & $\begin{array}{l}6^{\text {th }} \text { IEEE-GRSS } \\
\text { Young Professionals } \\
\text { and ISPRS Student } \\
\text { Consortium Brazil } \\
\text { Summer School }\end{array}$ & 512 \\
\hline
\end{tabular}




\begin{tabular}{|l|l|c|}
\hline $\begin{array}{l}\text { Classification of Land } \\
\text { Cover and Land Use } \\
\text { Based on Deep Learning }\end{array}$ & $\begin{array}{l}6^{\text {th }} \text { IEEE-GRSS } \\
\text { Young Professionals } \\
\text { and ISPRS Student } \\
\text { Consortium Brazil } \\
\text { Summer School }\end{array}$ & \\
& & \\
\hline
\end{tabular}

The number of reads for SpeCtrum significantly increased in 2020, with the special issue on COVID-10 receiving over 1,000 views (Table 2). In addition, a new section called "Special Feature" was added to the Newsletter. This section introduces and promotes organizations and online resources relevant to the profession. Some of the groups and initiatives featured include Women in Geospatial+, education and training resources on photogrammetry (grantee of the 2018 ISPRS Education and Capacity Building Initiatives), and Sisters of SAR.

Table 2. The number of reads for the special issues of the ISPRS SC Newsletter, SpeCtrum, taken from Scribd.

\begin{tabular}{|l|l|c|}
\hline Theme [Volume, Issue] & Actual Publication & $\begin{array}{l}\text { Number of } \\
\text { reads in } \\
\text { Scribd }\end{array}$ \\
\hline $\begin{array}{l}\text { The Roles of Geospatial } \\
\text { Information during the } \\
\text { COVID-19 Pandemic } \\
\text { [Volume 14, Issue 1] }\end{array}$ & $\begin{array}{l}\text { July 2020 } \\
\text { Link: } \\
\text { bit.ly/3sPmJBn }\end{array}$ & 1,115 \\
\hline $\begin{array}{l}\text { 3D GIS [Volume 14, } \\
\text { Issue 2] }\end{array}$ & $\begin{array}{l}\text { September 2020 } \\
\text { Link: } \\
\text { bit.ly/3iLLCJJ }\end{array}$ & 545 \\
\hline $\begin{array}{l}\text { SAR Remote Sensing } \\
\text { [Volume 14, Issue 3] }\end{array}$ & December 2020 & 504 \\
\hline
\end{tabular}

Many of the organization's online activities and events could be considered successful due to the online following that we have through social media that greatly magnified the reach of our announcements.

\subsubsection{Leadership and Service Mentoring Programme}

The ISPRS SC Board of Directors, given the extended term, worked on activities that can be promoted to foster meaningful connections among the organization's members and to further the advancement of their personal and professional skills. In order to train and familiarize aspiring applicants for the next Board of Directors, the Leadership and Service Mentoring Programme was launched in December 2020.

This programme primarily aims to train and familiarize qualified individuals with the responsibilities of the position they are interested in and about the activities of the Consortium. In addition, they will be involved and immersed in the actual work done by the current Board of Directors and will be given a set of milestones that must be achieved by the end of the programme. Lastly, this programme aims to provide skills necessary not only on the professional level, but also skills that can contribute to one's personal growth through cooperation and coordination of activities and the development of ideas to foster the career advancement and professional progress of the members of the Consortium. Outstanding mentees will be nominated by the current Board of Directors for the next ISPRS SC elections.
A total of seven mentees were accepted to the programme, with all positions in the Board of Directors with at least one mentee. Based on the questions asked during the application, the majority of the mentees became interested in getting more involved because of their participation in the Webinar Series and the Virtual Rooms. Furthermore, the opportunity of connecting with ISPRS experts through these online events motivated them to learn more about the ISPRS SC.

\section{THE ROLES OF THE ISPRS SC AS AN INTERNATIONAL STUDENT ORGANIZATION}

The ISPRS SC as an organization for the youth carries an important responsibility in shaping the future leaders and experts in our profession. We continue to revisit our roles as an international organization, evaluate the needs of our members, improve our existing activities and create new strategies and partnerships.

\subsection{Supporting Our Community}

A short survey related to the pandemic by the Newsletter team was disseminated to our members and on social media in June 2020. We wanted to understand the challenges that our members encountered and although only a limited number of responses was received, with only 18 participants, we were able to derive insights about the current situation (ISPRS SC, 2020b).

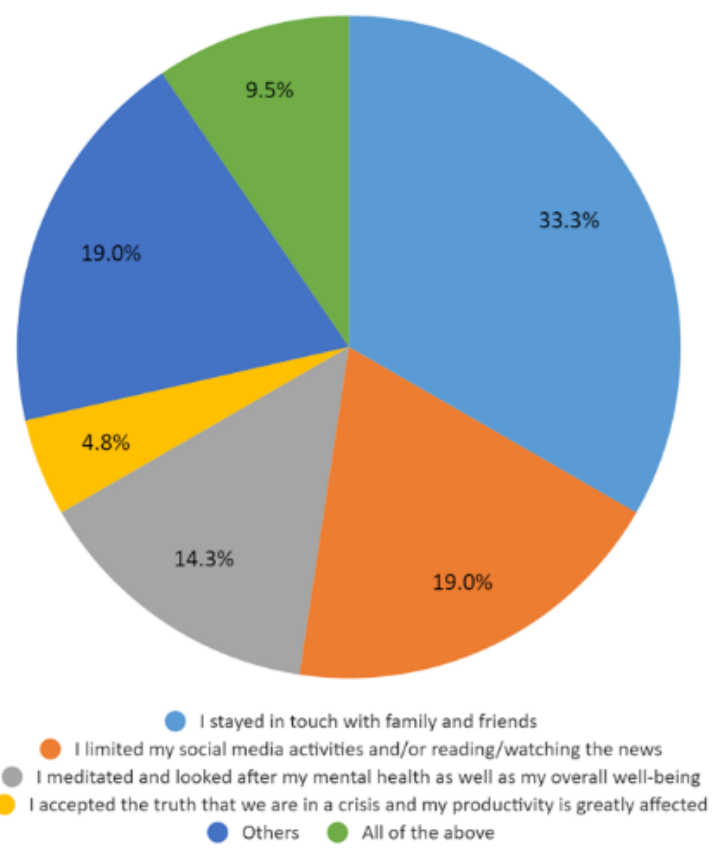

Figure 9. Survey responses from the short survey about coping with the pandemic. (Kindly note that these results are not representative of the Consortium).

From the survey, we learned that most of the members experienced inconsistencies with their daily productivity (Figure 9). Dealing with uncertainty, fear and grief caused by this pandemic was no small feat for students and young professionals. Understanding the importance of personal well-being was evident in the responses we received from the surveys. About $39 \%$ of respondents stayed in touch with their families and friends, $22 \%$ indicated that limiting social media engagement and watching the news less frequently were also strategies to keep moving forward, and $17 \%$ realized the importance of mental 
well-being. The significance of accepting the situation and that productivity was greatly affected proved to be helpful for some of the respondents as well as contributing or volunteering in initiatives in their locality that help in addressing some of the impacts of the pandemic.

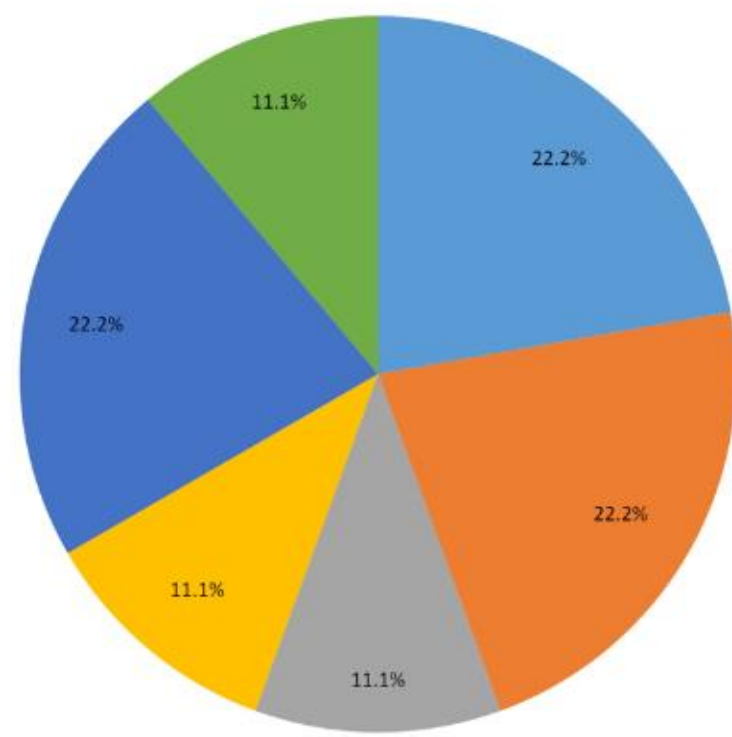

Connection and mindfulness Workplace flexibility Focus Optimism Work-life balance Others

Figure 10. Responses from participants related to the lessons learned from the pandemic. (Kindly note that these results are not representative of the Consortium).

Since our lifestyle and many of the ways we "normally' live our lives, do our work, study and socialize were altered to save more people, there were many lessons learned from this current situation. Connection and mindfulness, workplace flexibility and work-life balance were the main insights of the respondents with the changes that happened during the pandemic (Figure 10). Focus and optimism also contributed in doing work and accomplishing the goals set.

Moreover, some of the sessions in the ISPRS SC Virtual Rooms also provided support to our members. One of our invited guest speakers from the student support centre gave the participants some space to understand their current situation and valuable advice on managing personal challenges in this pandemic and how to find strength to keep moving forward. Women in Geospatial + was also invited for a presentation on inclusivity and diversity. A resource person from the University of the Philippines - Open University gave the final takeaway on how we can keep learning and teaching during this global health crisis.

\subsection{Leading as the Generation of "Digital Natives"}

As the representation of the younger generation in ISPRS, the ISPRS SC members are part of the so-called "digital natives," those who were born and raised with digital technology. As the world continues to transition and operate virtually, our roles now include providing support in understanding the available digital tools and contributing to a better scientific community.

\subsubsection{Bridging the Generation Gap}

By creating The Wisdom of the White Elephants in the Virtual Rooms, we had been granted the opportunity to work alongside the members of the ISPRS White Elephant Club. As the Knowledge Transfer Committee (ISPRS, 2020), their participation was highly valuable and most awaited by many of our participants. The feedback collected from the participants also cited how their advice helped in doing research and that learning from their lifelong experiences in the profession was a rewarding experience during this pandemic (ISPRS SC, 2020).

One of the main roles of the Consortium in this collaboration was to support the members of the White Elephant Club in familiarizing with the technology used to conduct these events, taking advantage of the digital connections we have and can create within the community (Van Bavel et al., 2020).

\subsubsection{Archiving Online Resources}

The Webinar Series, the special session in honour of Dr. Konecny in the Virtual Rooms, and the IEEE-GRSS Young Professionals and ISPRS Student Consortium Brazil Summer School were all live-streamed over YouTube and recordings were made available immediately after the event. The Virtual Rooms were organized in a meeting format, where participants and speakers were free to interact with one another so only the videos of the lectures were made available. The question-and-answer sessions that followed the Virtual Rooms were provided in audio format. All presentations related to the Webinar Series and the Virtual Rooms could be found in the official ISPRS SC website (Webinar Series: http://sc.isprs.org/isprs_sc_webinars.html; Virtual Rooms: http://sc.isprs.org/virtual-rooms.html).

In addition to making all these resources available to the general public, archiving our online resources enables us to understand the current trends and interests in our scientific community. It will also allow us to revisit the structure of these online events and activities for further improvement in the future.

\subsection{Building Resilience as a Scientific Community}

Our experiences in the ISPRS SC both prior and during the pandemic proved that building good relationships with local organizers, partner organizations and the Society contributed greatly to how we were able to adapt to changes. These experiences also demonstrated the immense advantage of working together as a community aiming to do better science and coping with major disruptions that can help establish our resilience to changes in the ways we organize and coordinate our activities.

\subsubsection{Fostering Collaboration}

The ISPRS SC Virtual Rooms, particularly, The ISPRS SC Super Friends, was one of the most successful rooms in this initiative. Despite the limited time to organize the sessions, many individuals and organizations generously gave their time and shared their knowledge to support the initiative.

Some organizations such as the Group on Earth Observations (GEO) and Esri provided insights on how ISPRS contributed and/or supported their organizations in addition to providing a wealth of information about their useful resources. Our participants also had the opportunity to learn about the development of space technology through projects and organizations such as Azercosmos in Azerbaijan and the Sustained Support for Local Space Technology \& Applications Mastery, Innovation and Advancement (STAMINA4Space) in the Philippines. Our connection to the United Nations Institute for Training and Research - Operational Satellite Applications 
Programme (UNITAR/UNOSAT) through our project MOTIVATE Learning (ISPRS, 2019) under the ISPRS Education and Capacity Building Initiatives 2018 paved the way for a session on the rapid disaster mapping of Typhoon Harold and how they made use of satellite imagery and other data to aid the local government.

Our social media presence also connected us to organizations that have been coordinating events in the remote sensing and geospatial communities. Our partnership in the GeoMixer event was due to a previous collaboration with the Ladies of Landsat (ISPRS SC, 2019b) and was extended to partnerships with other organizations, giving our members more opportunities to connect and meet students, professionals and experts in the profession outside of ISPRS.

\subsubsection{Strengthening Partnerships}

Through the Virtual Rooms and the Webinar Series, we have continued to connect ISPRS members and experts to the members of the Consortium and to bring the ISPRS SC (and ISPRS) branding in all of our online activities. As conferences started hosting their events online and with most of our professional exchanges happening virtually, these initiatives that were tailored to our audience proved to be more meaningful for our members during this pandemic. The feedback we received from the Virtual Rooms (ISPRS SC, 2020) mentioned that directly interacting with the guest speakers and with the members of the ISPRS White Elephant Club helped them cope with the challenges brought about by the lockdowns and quarantines.

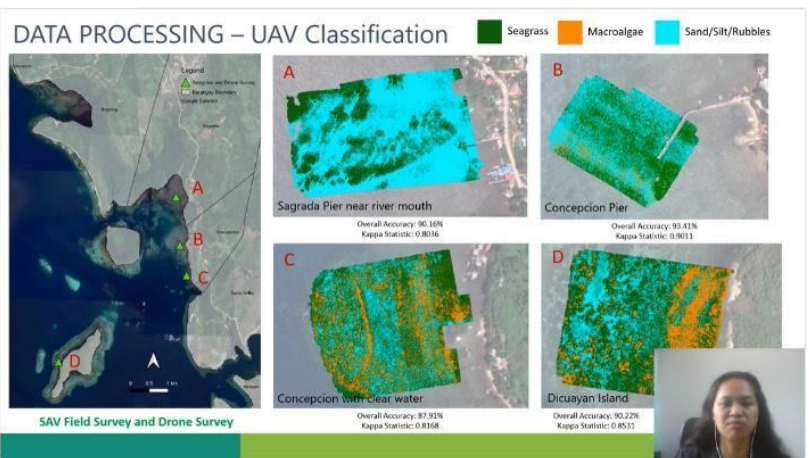

Figure 11. One of the presenters in the virtual edition of the ISPRS Congress under the Youth Forum track, Ms Ayin Tamondong of Tokyo Institute of Technology, presented her research titled, "Investigating the effects of river discharges on submerged aquatic vegetation using UAV and GIS techniques."

The Consortium also participated in the virtual edition of the ISPRS Congress 2020. Three presentations were delivered in the Youth Forum, including one live talk and two pre-recorded videos. It was hosted as a joint session with the Technical Commission V - Education and Outreach on September 1. The virtual edition was free of charge and was an incredible opportunity for our members to join in one of the largest scientific gatherings in our profession. The Youth Forum contributed a total 12 papers, three for the ISPRS Annals and nine for the ISPRS Archives for this edition of the ISPRS Congress.

For the last four years, the current ISPRS SC Board of Directors had been working with the local organizers from Brazil for the IEEE-GRSS Young Professionals and ISPRS Student Consortium Brazil Summer School. This partnership made it possible for the Consortium to host one summer school in 2020 and consider the possibilities of online lectures and training as well as summer schools with a hybrid format (a combination of in person meetings and live streams). The first lecture for this summer school was the most viewed video on our YouTube channel (refer to Table 1) and reached a thousand views in less than a week. Furthermore, the local organizers also extended the partnership again with SERFA 2020 through the special session that was delivered entirely in English. The summer school proved to be helpful to both the local organizers and the ISPRS SC in terms of increasing the number of international participants and providing an avenue for promotion of the organization and its activities.

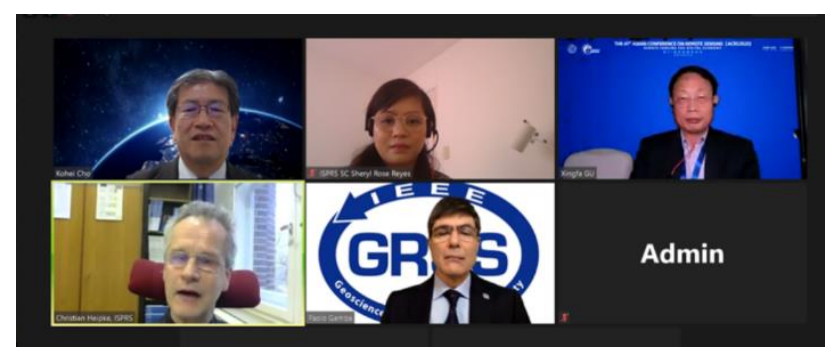

Figure 12. The panel discussion in ACRS 2020 on the roles of international academic societies in the pandemic.

Another conference that turned virtual in 2020 was the Asian Conference on Remote Sensing (ACRS 2020), organized annually by AARS and last year, together with Chinese National Committee for Remote Sensing (CNCRS). The current President of the ISPRS SC was invited to a special panel discussion related to the roles of international academic societies during this pandemic, together with Dr. Christian Heipke (ISPRS), Dr. Paolo Gamba (IEEE-GRSS), and Dr. Gu Xingfa (CNCRS) and the session was moderated by Dr. Kohei Cho (AARS). Although there was no summer school in this conference, the ISPRS SC was able to contribute by sharing our experiences during this pandemic (AARS, 2020).

\section{CONCLUSIONS}

In this paper, we summarized the activities and initiatives carried out by the ISPRS SC to support our members during the pandemic. Despite the challenges and adjustments, the organization continued to grow and sustained its contributions to the ISPRS and the scientific community. By learning how to adapt to change, lead the transition to digital knowledge exchange, nurture partnerships and collaborations and build resilience as a scientific community, the Consortium will continue to move forward and continue contributing for the advancements and progress in the ISPRS.

\section{ACKNOWLEDGEMENTS}

The ISPRS SC Board of Directors would like to express our deepest and sincerest gratitude to all the individuals and organizations that contributed our activities. We are also very thankful to our Design Team, namely, Sandra Pulmano, Vincent Louise Azucena, Amihan Manuel and Franz Raymond Bala for designing our amazing promotional materials and the Newsletter, for giving us their time and sharing their incredible talent. We also acknowledge the support of our proof-reader for the SpeCtrum, Andre Jonathan Obidos, for assisting us in ensuring the quality of our publications and our former Newsletter Editorin-Chief, Angelica Kristina Jaojoco for her assistance in this publication. A special mention to all the local organizers from Brazil for their perseverance and hard work during this challenging time. 


\section{REFERENCES}

AARS, (2020). The Panel Session on "Considering the Roles of International Academic Societies Under the Pandemic Crisis." Retrieved from https://a-a-r-s.org/2020/12/14/the-panel-session/.

Aristovnik, A., Keržič, D., Ravšelj, D., Tomaževič, N., \& Umek, L. (2020). Impacts of the COVID-19 pandemic on life of higher education students: A global perspective. Sustainability, 12(20), 8438 .

Brooks, S. K., Webster, R. K., Smith, L. E., Woodland, L., Wessely, S., Greenberg, N., \& Rubin, G. J. (2020). The psychological impact of quarantine and how to reduce it: rapid review of the evidence. The Lancet, 395(10227), 912-920.

Bonnett, A. (2016). The need for sustainable conferences. Royal Geogr. Soc., 38, 10.1111/j.1475-4762.2006.00710.x

Daniel, J. (2020). Education and the COVID-19 pandemic. Prospects, 49(1), 91-96.

Elmer, T., Mepham, K., \& Stadtfeld, C. (2020). Students under lockdown: Comparisons of students' social networks and mental health before and during the COVID-19 crisis in Switzerland. PLOS One, 15(7), e0236337.

Evans, T. M., Bira, L., Gastelum, J. B., Weiss, L. T., \& Vanderford, N. L. (2018). Evidence for a mental health crisis in graduate education. Nature Biotechnology, 36(3), 282-284.

GEM Report (2020). Coronavirus: could education systems have been better prepared? Retrieved from https://gemreportunesco.wordpress.com/2020/03/18/coronaviru s-could-education-systems-have-been-better-prepared/.

[Accessed 4 February 2021]

Granshaw, S. I. (2020). Konecny at 90: Elephants and crocodiles. The Photogrammetric Record 35(171): 344-356.

ISPRS (2019). MOTIVATE Learning: Making Opportunities to Initiate Valuable Alliance through Experiential Learning - Final Report. Retrieved from https://www.isprs.org/society/ecbi/ECBI-2018-SC-GISTDAMOTIVATE_Learning_Final_Report.pdf. [Accessed 4 February 2021]

ISPRS (2020). ISPRS Ad-hoc Committee "Knowledge Transfer." Retrieved from https://www.isprs.org/structure/knowledge_transfer.aspx.

[Accessed 4 February 2021]

ISPRS SC (2019a, August 15). Statutes. Retrieved from http://sc.isprs.org/about/isprs-sc/statutes.html.

ISPRS SC (2019b). Women in Remote Sensing and Geospatial Information. Retrieved from https://drive.google.com/file/d/1ZJXBQi9HkXyS7E06Uo8DFT fmYiljFVdR/view. [Accessed 4 February 2021]

ISPRS SC (2020, July). The Role of Geospatial Information During the COVID-19 Pandemic. Retrieved from http://sc.isprs.org/files/sc/newsletter/ISPRS-SC-Spectrum-

Vol14-No1.pdf. [Accessed 4 February 2021]
Lee, J. (2020). Mental health effects of school closures during COVID-19. The Lancet Child \& Adolescent Health, Volume 4, Issue 6, 2020, Page 421 .

Mathewson, T. G. (2020). Coronavirus is poised to inflame inequality in schools. Retrieved from https://hechingerreport.org/coronavirus-is-poised-to-inflameinequality-in-schools/. [Accessed 4 February 2021]

Pain, E. (2018). Graduate students need more mental health support, study highlights. Science.

Schwarz, M., Scherrer, A., Hohmann, C., Heiberg, J., Brugger, A., \& Nuñez-Jimenez, A. (2020). COVID-19 and the academy: It is time for going digital. Energy Research \& Social Science, 68,101684 .

Van Bavel, J. J., Baicker, K., Boggio, P. S., Capraro, V., Cichocka, A., Cikara, M., ... \& Willer, R. (2020). Using social and behavioural science to support COVID-19 pandemic response. Nature human behaviour, 4(5), 460-471.

World Health Organization (2020, March 11). WHO DirectorGeneral's opening remarks at the media briefing on COVID-19 11 March 2020. Retrieved from https://www.who.int/directorgeneral/speeches/detail/who-director-general-s-openingremarks-at-the-media-briefing-on-covid-19---11-march-2020. [Accessed 4 February 2021]

UNESCO (2021). UNESCO figures show two thirds of an academic year lost on average worldwide due to COVID-19 school closures. Retrieved from https://en.unesco.org/news/unesco-figures-show-two-thirdsacademic-year-lost-average-worldwide-due-covid-19-school. [Accessed 4 February 2021] 